\title{
PERSEPSI KARYAWAN FRONT OFFICE DEPARTMENT HOTEL TERHADAP BUDAYA TIPPING
}

\author{
Calvin Mercy Ebenhaezer Watulingas ${ }^{1}$, *V. Ratna Inggawati ${ }^{2}$ \\ 1,2 Universitas Katolik Darma Cendika \\ *) vincentia.ratna@ukdc.ac.id
}

\begin{tabular}{l}
\hline Informasi Artikel \\
\hline Draft awal: \\
Revisi : \\
Diterima : \\
Available online: \\
\hline
\end{tabular}

Keywords: Perception, Culture of Tipping, Front Office Department

Tipe Artikel : Research paper

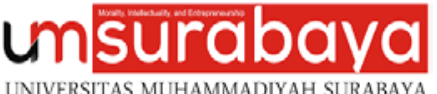

Diterbitkan oleh Universitas Muhammadiyah Surabaya

\begin{tabular}{|c|}
\hline \\
\hline $\begin{array}{l}\text { Tipping is now a common thing for Indonesians, especially in the } \\
\text { spitality sector. In order to maintain the quality provided to remain good, } \\
\text { lequate quality of human resources is needed. For employees who are } \\
\text { en to have provided satisfactory service, one form of consumer } \\
\text { preciation is to provide bonuses in the form of tips. }\end{array}$ \\
\hline $\begin{array}{l}\text { This research is to see how employees perceive the tipp } \\
\text { which involves front office department employees and consum } \\
\text { star hotels in East Surabaya. This study uses a descriptive ap } \\
\text { interviews as a data collection technique. From each hotel } \\
\text { employees and } 2 \text { consumers who represent the research sh } \\
\text { results showed that there were } 2 \text { tip distribution systems, na } \\
\text { distribution (individual) and the same tip distribution (collective } \\
\text { the sharing of tips (individual) system often creates conf } \\
\text { application, so it needs special attention from the hotel manas } \\
\text { employees who receive, Tips can increase motivation, reward } \\
\text { achievements), volunteer money from guests and additional } \\
\text { savings. Also that the tip is an appreciation of the attitude of em } \\
\text { are polite, friendly, and responsive in dealing with consumer } \\
\text { staying at the hotel }\end{array}$ \\
\hline $\begin{array}{l}\text { merupakan hal yang umum dilakukan } \\
\text { pada bidang perhotelan. Untuk menjaga } \\
\text { r tetap baik, dibutuhkan kualitas sumber } \\
\text { agi karyawan yang dipandang telah } \\
\text { uaskan, salah satu bentuk apresiasi } \\
\text { an bonus berupa tip. }\end{array}$ \\
\hline $\begin{array}{l}\text { yawan front office department } \\
\text { ada di Surabaya Timur. Peneliti } \\
\text { eskriptif dengan wawancara se } \\
\text { sing-masing hotel dipilih } 3 \\
\text { g mewakili subjek penelitian. } \\
\text { at } 2 \text { sistem pembagian tip yai } \\
\text { I sharing of tips (kolektif). N }\end{array}$ \\
\hline
\end{tabular}

\section{ABSTRACT} \begin{abstract}
hospitality sector. In order to maintain the quality provided to remain good, adequate quality of human resources is needed. For employees who are seen to have provided satisfactory service, one form of consumer
\end{abstract}

This research is to see how employees perceive the tipping culture, which involves front office department employees and consumers at 4 IIIstar hotels in East Surabaya. This study uses a descriptive approach with employees and 2 consumers who represent the research subjects. The results showed that there were 2 tip distribution systems, namely no tip the sharing of tips (individual) system often creates conflicts in its application, so it needs special attention from the hotel management. For employees who receive, Tips can increase motivation, rewards (personal achievements), volunteer money from guests and additional salary for savings. Also that the tip is an appreciation of the attitude of employees who are polite, friendly, and responsive in dealing with consumer complaints staying at the hotel

oleh masyarakat Indonesia terutama pada bidang perhotelan. Untuk menjaga kualitas layanan yang diberikan agar tetap baik, dibutuhkan kualitas sumber daya manusia yang memadai. Bagi karyawan yang dipandang telah memberikan layanan yang memuaskan, salah satu bentuk apresiasi konsumen adalah dengan memberikan bonus berupa tip.

Penelitian ini untuk melihat bagaimana persepsi karyawan terhadap budaya tipping, yang melibatkan karyawan front office department serta konsumen di 4 hotel bintang III yang ada di Surabaya Timur. Penelitian ini menggunakan pendekatan kualitatif deskriptif dengan wawancara sebagai teknik pengambilan data. Dari masing-masing hotel dipilih 3 orang karyawan dan 2 orang konsumen yang mewakili subjek penelitian. Hasil penelitian menunjukkan bahwa terdapat 2 sistem pembagian tip yaitu no system sharing of tips (individual) sering menimbulkan konflik dalam penerapannya, sehingga perlu perhatian khusus dari pihak manajemen hotel. Bagi karyawan yang menerima, Tip mampu meningkatkan motivasi, penghargaan (personal achievement), uang sukarela dari tamu (guess tanggap dalam mengatasi komplain konsumen yang menginap di Hotel

\section{PENDAHULUAN}

Perhotelan di Indonesia, merupakan industri yang dinamis, dimana salah satu indikator pengukuran keberhasilan bisnis hotel adalah tingkat penghunian kamar (TPK). Tinggi rendahnya TPK hotel sangat dipengaruhi oleh dua faktor yaitu faktor internal dan ekstenal. Faktor 
internal ialah faktor dari dalam hotel itu sendiri yaitu fasilitas-fasilitas yang dimiliki oleh hotel dan juga kualitas pelayanannya, sedangkan yang dimaksud faktor eksternal ialah faktor dari luar perusahaan, yaitu faktor sosial, ekonomi, teknologi dan kebijakan pemerintah. Data dari BPS Jawa Timur menunjukkan bahwa rata-rata TPK seluruh jenis hotel, baik berbintang atau usaha akomodasi lainya yang ada di Jawa Timur terus mengalami peningkatan tiap tahunnya, dengan peningkatan rata-rata TPK dari 46,71\% menjadi 51,78\% pada bulan Januari 2015 hingga Nopember 2016, sedangkan pada tahun 2016 hingga 2017 terus mengalami peningkatan dari 44,02\% menjadi 50,99\% (BPS Jawa Timur 2016). Peningkatan TPK tersebut merupakan indikasi jumlah tamu yang menginap pada hotel berbintang juga mengalami peningkatan.

Produk inti hotel adalah jasa akomodasi, namun jasa harus disertai dengan layanan, karena tamu tidak hanya sekedar menginap tetapi juga menginginkan nilai tambah dari yang telah dibayarkan. Menjamurnya hotel-hotel berbintang di kota besar memicu persaingan yang ketat dimana setiap hotel berbintang berlomba - lomba untuk memberikan layanan yang terbaik. Layanan yang diberikan karyawan merupakan strategi yang digunakan oleh hotel-hotel untuk meningkatkan competitive advantage. Kualitas sumber daya manusia yang memadai menjadi syarat mutlak untuk menjaga kualitas layanan yang diberikan tetap baik sesuai yang dibutuhkan oleh konsumen. Goldsmith, dkk. (2002) menyatakan bahwa efektivitas organisasi di bidang jasa sangat terkait dengan kualitas individual karyawan. Apabila karyawan dipandang telah memberikan layanan yang memuaskan, maka akan muncul apresiasi dari konsumen kepada karyawan. Salah satu bentuk apresiasi konsumen adalah memberikan bonus lebih berupa tip (M Lynn, 2001).

Asal mula kata "tip" muncul pada abad ke-17, dimana kata "tip" berarti "memberikan kepada" atau "memberi” (Obringer, 2002:1) Sedangkan menurut Matthews (2005), tip adalah sebuah hadiah atau pemberian, biasanya berbentuk uang, yang diberikan sebagai imbalan atas sebuah layanan. Tipping sendiri adalah sebuah fenomena yang menggambarkan dengan jelas bahwa perilaku ekonomi sering dimotivasi oleh norma norma sosial dan alasan psikologis (Azar, 2003). Di Amerika, tipping sudah menjadi norma sosial (Azar, 2007). Apabila seseorang tidak memberi tip, akan dianggap melanggar etika atau tidak sopan (Azar, 2003). Sebaliknya, para konsumen akan merasa adanya sebuah tekanan sosial untuk memberi tip (M Lynn, 2001).

Bagi karyawan, tip merupakan salah satu sarana untuk mendapatkan penghasilan yang lebih, yang diharapkan dapat membantu memenuhi kebutuhannya, karena secara tidak langsung akan mendapatkan penghasilan tambahan (Lin \& Namasivayam, 2011). Adapun setiap hotel memiliki sistem pembagian tip yang berbeda-beda. Ada 2 macam sistem pembagian tip, yaitu pembagian sama rata dan pembagian individu dimana setiap karyawan yang menerima tip akan menyimpan sendiri masing-masing tip yang didapat (Lin \& Namasivayam, 2011). Dari sisi karyawan, terdapat pandangan yang berbeda mengenai kedua sistem pembagian tip diatas. Penelitian yang dilakukan di Amerika, (Namasivayam \& Upneja, 2007) mempelajari bahwa ada beberapa karyawan yang menganggap bahwa pembagian tip yang sama rata merupakan yang paling adil, namun ada juga beberapa karyawan yang berpendapat bahwa sistem pembagian tiping per individu adalah yang paling adil, karena hal sesuai dengan hasil kerjanya.

Gatta (2009) menyatakan bahwa sistem pembagian tip adalah suatu hal yang harus diperhatikan oleh manajemen karena kompensasi yang layak dan pembagian tip yang adil merupakan indikator penting yang dapat berpengaruh pada motivasi, efisisensi dan kinerja karyawan. Van Den Bos, K. (2001:932) menyatakan bahwa "setiap orang membutuhkan kepastian akan keadilan ketika dihadapkan kepada aspek-aspek dalam hidup yang tidak menentu”. Gatta (2009:75) menyatakan bahwa karyawan akan berlomba untuk bekerja pada peak-hour dalam rangka untuk meningkatkan tip yang didapatkan. Akan muncul ketidakadilan yang dirasakan disaat seorang karyawan beranggapan bahwa dirinya menerima hasil yang lebih sedikit tetapi berkontribusi lebih banyak dibandingkan rekan kerja lainnya (Lin \& Namasivayam, 2011). Penelitian tersebut menjelaskan bahwa tip mempengaruhi penilaian karyawan akan keadilan, sehingga karyawan memiliki sensitivitas yang tinggi akan sistem pembagian tip yang adil.

Tipping juga memegang peranan yang penting dalam hubungan antara perusahaan dan karyawan, dimana tipping dapat menarik, memotivasi, dan mengontrol karyawan (Lynn \& Wang, 2017). Selanjutnya dikatakan bahwa tip memberikan motivasi kepada karyawan untuk bekerja keras dan memberikan kualitas layanan yang 
memuaskan bagi konsumen. Hal ini dapat berpengaruh pada kualitas layanan yang diberikan oleh karyawan, contohnya seorang bartender akan menuangkan minuman lebih banyak untuk tamu secara gratis agar mendapatkan tip. Hal ini dapat memberikan dampak positif bagi tamu yang akan merasa puas dan senang terhadap layanan yang telah diberikan, namun hal tersebut akan berdampak negative bagi hotel yang akan mengalami kerugian (Lynn, 2014). (Namasivayam \& Upneja, 2007) berpendapat bahwa motivasi karyawan untuk memberikan layanan yang baik tidak berpengaruh oleh jumlah tip yang diberikan oleh konsumen, sedangkan Kwortnik dkk. (2009) menilai bahwa jumlah tip yang diterima mempengaruhi layanan yang diberikan, dan efeknya berbeda untuk masing-masing individu. Berbagai fakta yang diungkap berdasarkan penelitian-penelitian sebelumnya, dapat dilihat adanya fenomena bahwa tip dapat mempengaruhi kualitas layanan yang diberikan para karyawan. Namun demikian, penelitian mengenai tipping, terlebih lagi di Indonesia masih minim dilakukan.

Teori dan konsep tentang tipping dijelaskan sebagai berikut:

\section{Sejarah Tipping}

Sejarah tipping sudah dimulai dari dahulu sejak era Romawi dan mungkin lebih lama lagi. Menurut (Azar, 2007), tipping adalah cara untuk memberi imbalan atau hadiah untuk para budak dan server. Sedangkan (Whaley, 2011) mengatakan pada era tahun 1900-an ketika tip berubah dari pemberian reward setelah service dilakukan menjadi pemberian reward sebelum adanya service, server pun terlihat bekerja lebih malas dan lebih arogan serta tidak ada upaya untuk memberikan service yang lebih kepada para konsumen. (Conlin dkk., 2003) mengungkapkan bahwa para pakar ekonomi menyatakan bahwa tipping ada karena hal tersebut adalah cara yang paling efisien untuk meningkatkan service quality dari paraserver. Selanjutnya (Conlin dkk., 2003) juga mengungkapkan bahwa tipping bisa menjadi alat untuk mengawasi dan memberikan hadiah atas usaha para server. Para ahli berpendapat bahwa kebiasaan memberikan tip muncul karena hal ini merupakan jalan paling efisien untuk mendorong para pekerja melakukan pekerjaannya dengan baik.

\section{Pengertian Tip}

Beberapa ahli seperti (Michael Lynn \& Sturman, 2010) mendefinisikan tip sebagai hadiah/balasan kepada pemberian service yang baik. Sedangkan (Whaley, 2011) mengungkapkan:
"Tipping telah terbentuk di dalam suatu pekerjaan dimana konsumen dapat merasakan empati dan iba kepada para pekerja karena rendah atau tingginya pendapatan para pekerja." Menurut (Azar, 2007) tipping atau "To Insure Promptitude" (T.I.P), sudah ditemukan di Inggris di era tahun 1600-an, dimana tip pertama kali digunakan di sebuah kedai kopi dan selanjutnya digunakan di pub local. Tip diberikan oleh konsumen yang ingin mendapatkan service khusus dengan cara meletakkan koin terlebih dahulu di dalam kotak yang bertuliskan "To Insure Promptitude" (T.I.P).Pengertian lain mengenai tipping juga diungkapkan oleh Matthews (2005) yang memberikan dua definisi mengenai tip: 1) Tip dimaksudkan sebagai keputusan pribadi seseorang untuk mengungkapkan rasa puas terhadap kualitas layanan yang telah didapat. 2) Tip diartikan bukan sebagai suatu permintaan, akan tetapi sebagai suatu pemberian dalam bentuk uang, yang diberikan secara sukarela sebagai penghargaan terhadap para server atau jasa service yang telah diberikan yang dianggap mampu memuaskan konsumen.

\section{Konsep Persepsi}

Sarwono dalam Sugiarto (2015:12) mengungkapkan bahwa persepsi merupakan salah satu aspek psikologis yang penting bagi manusia dalam merespon kehadiran berbagai aspek dan gejala di sekitarnya. Persepsi mengandung pengertian yang sangat luas, menyangkut intern, dan ekstern. Berbagai ahli telah memberikan definisi yang beragam tentang persepsi, walaupun pada prinsipnya mengandung makna yang sama. Menurut Kamus Besar Bahasa Indonesia, persepsi adalah tanggapan (penerimaan) langsung dari sesuatu, atau proses seseorang mengetahui beberapa hal melalui panca inderanya. Sugihartono, et. al (2007:8) mengemukakan bahwa: Persepsi adalah kemampuan otak dalam menerjemahkan stimulus atau proses untuk menerjemahkan stimulus yang masuk ke dalam panca indera manusia. Persepsi manusia terdapat perbedaan sudut pandang dalam penginderaan. Ada yang mempersepsikan sesuatu itu baik atau persepsi negatif yang akan mempengaruhi tindakan manusia yang tampak atau nyata.Setiap orang memiliki kecenderungan dalam melihat benda yang sama dengan cara yang berbeda-beda. Perbedaan tersebut bisa dipengaruhi oleh banyak faktor, diantaranya adalah pengetahuan, pengalaman, dan sudut pandangnya. Persepsi juga bertautan dengan cara pandang seseorang terhadap 
suatu objek tertentu, dengan cara yang berbedabeda dengan menggunakan alat indera yang dimiliki, kemudian berusaha untuk menafsirkannya. Persepsi, baik positif maupun negatif ibarat file yang sudah tersimpan rapi di dalam alam pikiran bawah sadar. File itu akan segera muncul ketika ada stimulus yang memicunya, ada kejadian yang membukanya. Persepsi merupakan hasil kerja otak dalam memahami atau menilai suatu hal yang terjadi di sekitarnya. (Waidi, 2006:118). Sedangkan menurut Suharman (2005:23), persepsi merupakan suatu proses menginterpretasikan atau menafsir informasi yang diperoleh melalui sistem alat indera manusia.

\section{Tujuan, Motivasi, dan Keuntungan Memberikan Tip}

Azar (2007) mengemukakan bahwa keinginan tersendiri dari setiap individu dalam memberikan tip sebagai reward atas pekerjaan para server sangatlah positif terhadap tip size yang diberikan. Tujuan memberikan tip secara teoritis, diungkapkan oleh Duman dan Pulliam (2006), yaitu untuk meningkatkan kinerja server dan untuk mengurangi jumlah pajak yang harus dibayar oleh server. Selanjutnya motivasi untuk memberikan tip didasari pada oleh beberapa hal berikut (tipping.org dalam Mandias, 2006): (1) Membayar pelayanan yang didapat, (2) Merupakan imbalan yang diberikan untuk para server atas pelayanan dalam pengiriman makanan ke meja para konsumen, meskipun sifatnya adalah opsional. (3) Konsumen merasa diperlakukan dan dilayani dengan baik (4) Sebagai bentuk balasan dari perhatian dan pelayanan yang baik dari server. (5) Gaji server yang dipandang kecil (6) Pekerjaan server yang sangat berat dan penuh tekanan, (7) Pemberian tip adalah hal yang tidak wajib, karena pemberian tip bukan sebuah keharusan bagi seluruh konsumen, (8) Gengsi karena tingginya tekanan sosial yang ada pada era ini sehingga membuat para konsumen memberikan tip karena peduli akan tanggapan orang lain kepada dirinya. (9) konsumen merasa menjadi baik hati dengan memberikan tip

\section{METODE PENELITIAN}

Obyek penelitian ini adalah persepsi terhadap budaya tipping di Departemen Front Office Hotel di Surabaya Timur, maka peneliti menggunakan jenis penelitian kualitatif deskriptif. Laporan penelitian berisi data-data untuk memberikan gambaran penyajian yang berasal dari naskah, wawancara, catatan lapangan, laporan, dokumen pribadi, catatan atau memo, dan dokumen resmi lainnya. Pada penulisan laporan deskriptif, peneliti menganalisis data sejauh mungkin dalam bentuk aslinya.

Jenis data yang digunakan dalam penelitian ini adalah data kualitatif. Peneliti menggunakan Teknik Analisa data:

1. Analisa Deskriptif, yang akan menguraikan data dan memberikan gambaran secara deskriptif mengenai hasil pengamatan dan wawancara dengan responden.

2. Analisa Evaluatif, yang akan mengevaluasi data yang telah diperoleh yaitu dengan mencocokan hasil wawancara dengan keadaan sesungguhnya dilapangan.

3. Melakukan Uji Kredibilitas dan Reliabilitas. Uji kredibilitas data atau kepercayaan terhadap data hasil penelitian kualitatif antara lain dilakukan dengan perpanjangan pengamatan, peningkatan ketekunan dalam penelitian, triangulasi, diskusi dengan teman sejawat, analisis kasus negatif, dan member check. Uji Reliabilitas menurut Sugiyono (2015:211), dalam penelitian kuantitatif, dependability disebut reliabilitas. Suatu penelitian yang reliabel adalah apabila orang lain dapat mengulangi/mereplika proses penelitian tersebut. Dalam penelitian kualitatif, uji dependability dilakukan dengan melakukan audit terhadap keseluruhan proses penelitian. Dalam penelitian ini peneliti melakukan uji reliabilitas dengan cara melakukan peninjauan kembali setelah satu minggu dari hari wawancara kepada informan. Hal ini dilakukan untuk melihat konsistensi jawaban seputar persepsi budaya tipping.

Penarikan kesimpulan dilakukan setelah menganalisa dan membahas hasil penelitian dan memberikan saran dari sudut pandang peneliti untuk lebih mendukung penelitian ini.

\section{HASIL DAN PEMBAHASAN}

\section{Hasil}

\section{Profil Pekerjaan Informan}

Concierge secara struktural posisi concierge dalam front office department memiliki tugas dan tanggung jawab sendiri dalam kesehariannya. Bersama dengan Front Desk Attendance sering kali posisi concirerge menjadi wajah sebuah hotel untuk banyak tamu. Concierge section adalah yang paling pertama dan terakhir dalam memberikan pelayanan saat pertama kali tamu tiba dan saatakan meninggalkan hotel, dan 
dari sini tamu biasa memberikan penilaian mengenai pelayanan yang diberikan hotel secara umum. Pelayanan concierge yang diberikan tidak terbatas hanya pada pelayanan atau penyimpanan barang. Lebih dari itu seorang concierge harus paham dan memiliki pegetahuan yang luas mengenai hotel dan local area di luar hotel. Tamu akan datang dan mendekati concierge dengan membawa pertanyaan, mencari saran dan berbagai macam permintaan solusi masalah. Di dalam penelitian ini terdapat satu orang concierge yang berpartisipasi.

Front Desk Attendance merupakan salah satu komponen penting yang ada di hotel. Saat pertama kali tamu datang, langsung berinteraksi dengan front desk attendance untuk melakukan proses check in dan menerima pembayaran.

Guest Relation Officer adalah petugas yang berhubungan langsung dengan tamu, mereka adalah orang pertama yang menyambut dan memberikan salam pada saat tamu tiba. Demi memberikan pelayanan yang terbaik kepada tamu seorang Guest Relation Officerharus memastikan selama tamu menginap mereka mendapatkan kesan atau pelayanan yang tak terlupakan. Posisi Guest Relation Officer juga memastikan tamu merasa senang dan nyaman sejak pertama kali mereka menginjakkan kaki sampai mereka pergi meninggalkan hotel.

Greeter and bel boy. Seorang Greeter bertugas sebagai penyambut tamu yang masuk ke lobby hotel, dan mengarahkannya untuk melakukan check in process. Petugas biasanya adalah seseorang yang mempunyai kemampuan bahasa asing aktif. Seorang greeter biasanya juga merangkap sebagai bell boy untuk mengantarkan barang-barang yang dibawa oleh tamu ke kamarnya menggunakan trolley.

Tabel 1 Menunjukkan Informan Yang Berpartisipasi Dalam Penelitian.

\begin{tabular}{|c|c|c|c|c|c|}
\hline $\begin{array}{l}\text { Informan } \\
\text { ke }\end{array}$ & Usia & $\begin{array}{c}\text { Jenis } \\
\text { Kelamin }\end{array}$ & $\begin{array}{c}\text { Status } \\
\text { Marital }\end{array}$ & $\begin{array}{c}\text { Lama Bekerja } \\
\text { (Thn) }\end{array}$ & Keterangan \\
\hline 1 & 23 & Wanita & Lajang & 2 & Front Desk Attendant \\
\hline 2 & 28 & Pria & Lajang & 2,5 & Duty Manager FO \\
\hline 3 & 21 & Wanita & Lajang & 2 & Guest Relation Officer \\
\hline 4 & 24 & Pria & Menikah & 1 & Duty Manager FO \\
\hline 5 & 27 & Pria & Lajang & 1,5 & Greeter and Bell Boy \\
\hline 6 & 20 & Wanita & Lajang & 2,5 & Bell Driver \\
\hline 7 & 28 & Wanita & Lajang & 3 & Front Desk Attendant \\
\hline 8 & 30 & Pria & Menikah & 3 & Guest Relation Officer \\
\hline 9 & 24 & Pria & Lajang & 3,5 & Concierge \\
\hline 10 & 26 & Pria & Lajang & 2 & Greeter and Bell Boy \\
\hline 11 & 23 & Wanita & Lajang & 1,5 & Front Desk Attendant \\
\hline 12 & 27 & Pria & Lajang & 2 & Greeter and Bell Boy \\
\hline 13 & 33 & Pria & Menikah & 1 & Consumer \\
\hline 14 & 26 & Wanita & Lajang & & Consumer \\
\hline 15 & 40 & Pria & Menikah & & Consumer \\
\hline 16 & 52 & Wanita & Menikah & & Consumer \\
\hline 17 & 29 & Wanita & Lajang & & Consumer \\
\hline 18 & 34 & Pria & Menikah & & Consumer \\
\hline 19 & 29 & Pria & Menikah & & Consumer \\
\hline 20 & 39 & Pria & Lajang & & Consumer \\
\hline
\end{tabular}

Tabel 1 menjelaskan informan yang telah ditetapkan sebanyak 20 orang yang terdiri dari 12 orang staffFront Office Departement dan 8 orang konsumen dari 4 hotel yang telah ditetapkan, yaitu masing-masing sebanyak 3 (tiga) orang karyawan dan 2 (dua) orang konsumen. Peneliti memilih informan yang bekerja di Front Office Departement karena 
departemen inilah yang dianggap paling sering berinteraksi dengan tamu dan mendapatkan tip. Selain itu peneliti juga memilih informan dengan jabatan yang berbeda-beda dalam satu divisi front office agar data yang diperoleh lebih dalam dan bervariasi sehingga dapat dibandingkan antar pekerjaan. dilakukan:

Berikut adalah hasil wawancara yang

Informan 1 yang ada di divisi front desk attendancemenyatakan bahwa budaya tipping diijinkan pada divisi front office. Dimana pada area front desk, sistem pembagian tippingnya individual kolektif. Artinya setiap karyawan yang mendapatkan tip, akan menyimpan terlebih dahulutip yang diperoleh secara kolektif di cash box. Menurutnya, cara tamu memberikan tip untuk front desk attendance cukup unik yaitu sisa uang kembalian pada saat tamu melakukan pembayaran tidak diminta oleh tamu, dengan begitu maka uang kembalian yang tersisa akan menjadi milik front desk attendance yang menangani tamu tersebut, yang kemudian akan diperhitungkan sesuai yang didapat masingmasing karyawan yang bertugas. Beliau menyatakan tidak banyak tamu memberikan tip serta tidak rutin, beliau menyatakan estimasi tip di front desk attendance berkisar Rp.300.000,dalam sebulan. Beliau beranggapan bahwa hal seperti pemberian tip sering ditemukan di divisi concierge. Tip yang pernah ia dapat juga pernah dalam bentuk barang, entah makanan atau aksesoris, justru menurut beliau pemberian dalam bentuk goods lebih sering daripada nominal uang untuk front desk attendance. Tamu yang sering memberikan tip adalah tamu regular guest dan in-house guest. Biasanya, ketika pembagian tip dilakukan dan ada yang mendapatkan tip dengan nominal cukup besar, akan berinisiatif untuk membeli makanan yang dikonsumsi bersama-sama dengan rekan dari divisi lain di front office.

Semua informan yang berstatus sebagai karyawan menyatakan bahwa sistem tipping yang dijalankan di outlet front office adalah sistem tipping individual. Hal ini senada dengan pernyataan (Lin \& Namasivayam, 2011) bahwa terdapat dua sistem tipping yang berlaku pada suatu hotel di antaranya yaitu sistem tipping individual maupun sistem tipping kolektif. Beberapa informan mengungkapkan bahwa divisi concierge adalah divisi yang paling banyak dan sering mendapatkan tip, namun hal itu dapat diterima dengan baik oleh divisi lain, karena bagi mereka hal tersebut sepadan dengan kerja fisik yang harus dilakukan oleh rekanrekannya di divisi concierge. Bahkan informan 3 menyebutkan "concierge juga udah capek angkat barang, jadi sebandinglah”. Oleh karena itu sistem tipping kolektif tidak dijalankan di departemen ini, guna meredam perselisihan antar karyawan front office di tiap divisi.

Lebih lanjut, pendapatan tip yang didapatkan oleh informan yang bekerja di front office tidak memiliki nominal pasti dan memiliki kisaran dari Rp 50.000, - - Rp 300.000,-. Hal ini dikarenakan banyak tidaknya jumlah tip yang didapat bergantung pada tinggi rendahnya occupancy serta ramai tidaknya suatu outlet.

Sebagian besar informan menyatakan bahwa jabatan bisa mempengaruhi jumlah tip yang didapat, tetapi hal tersebut tidak menimbulkan kecemburuan sosial antar staff di tiap divisi yang ada di front office. Oleh karena itu, peneliti menyimpulkan bahwa sistem tipping individual cukup adil untuk departemen front office,berbeda kasus jika departemen lain ikut campur seperti pernyataan informan 4 yang menyatakan bahwa "kesenjangan ini terkadang terjadi antara concierge dan security". Dari kasus ini akhirnya menunjukkan bahwa ada kecemburuan sosial yang terjadi antar karyawan satu hotel yang berlainan department, meskipun seluruh informan yang bekerja sebagai karyawan frontoffice menyatakan sudah adil untuk departemen mereka sendiri, akan tetapi ternyata setelah ditelusuri lebih dalam kepada informan 9 sebagai conciergemenyatakan bahwa hal yang menyebabkan timbulnya kesenjangan tersebut adalah karena staff yang on duty pada shiftnya sedikit, sehingga tidak heran akhirnya meminta bantuan kepada rekan-rekan departemen security. Akan tetapi pembahasan lebih detail informan 9 katakan yang menyebabkan perselisihan terkadang dalam melayani tamu menjadi saling memperebutkan luggage up saat check-in ataupun luggage down saat checkout,yang bertujuan untuk mendapatkan tip, padahal hal tersebut bukan job description dari tim security. Saran peneliti untuk kondisi ini pihak front office manager/duty manager ialah memperhatikan sistem pembagian tipping, sesuai dengan pernyataan Gatta (2009) yang menyatakan bahwa karyawan akan berlomba untuk bekerja pada peak hour dalam rangka mendapatkan tip lebih banyak. 
Seluruh informan sebagai karyawan front office menyatakan sangat setuju bahwa tip bukan hal utama yang dicari dalam melakukan pelayanan ke tamu tetapi dianggap sebagai pendapatan tambahan saja, untuk tabungan dan investasi pribadi sebagaimana pernyataan informan 6, maupun pernyataan informan 7 "we still doing great with or without the tips itself", karena sebagai staff front office pelayanan maksimal adalah sebuah keharusan bukan opsi atau terstimulus oleh tip.

Lebih jauh, para karyawan juga menyatakan sangat setuju bahwa tip memberikan motivasi untuk bekerja keras dan memberikan kualitas layanan yang memuaskan bagi tamu. Hal tersebut sesuai dengan pendapat (Michael Lynn \& Sturman, 2010), dan (Azar, 2007) yang menyatakan tip mampu meningkatkan motivasi karyawan untuk bekerja lebih baik dan giat, sehingga akan memberikan kualitas layanan terbaik kepada konsumen dan ketika konsumen merasa puas, diharapkan akan memiliki loyalitas. Dari berbagai pernyataan informan yang bekerja di front office department, dapat disimpulkan jika tip tidak mempengaruhi pelayanan yang diberikan, berbeda dengan pernyataan Kwortnik $d k k$. (2011) yang menyatakan bahwajumlah tip yang diterima bisa mempengaruhi layanan yang diberikan.

Dari berbagai pernyataan di atas peneliti juga mendapati bahwa informan yang bekerja di front office department mengutamakan kekeluargaan, kebersamaan, kerja sama untuk menjadi tim yang solid. Menurut pengamatan peneliti di departemen front office, karyawan yang bekerja disini sudah terlatih untuk melakukan pelayanan dengan caraservice sequence yang ditangani hanya dengan satu orang saja. Dengan kata lain, sikap dan persepsi karyawan dalam memandang tipping kemungkinan dipengaruhi oleh faktor lain seperti working environment, rasa kebersamaan, dan teamwork di antara karyawan pada suatu departemen. Seperti pernyataan informan 2 yang menjabat sebagai duty manager front office, beliau menyatakan bahwa di front office dibagi menjadi dua sistem yaitu collective tipping system untuk rekan-rekan Front Desk Attendance, Guest Relation Officer, Supervisor dan Manager, sedangkan untuk Concierge lebih ke individual tipping system. Dengan membagi praktek seperti ini mampu meminimalisir rasa ketidakadilan kerja, dan akhirnya bisa membangun kebersamaan tim. Hal ini sesuai pernyataan Gatta (2009) bahwa sistem pembagian tip adalah suatu hal yang harus diperhatikan oleh manajemen karena hal tersebut merupakan indikator yang dapat berpengaruh pada motivasi, efisiensi, kinerja karyawan dan diharapkan bisa meminimalisir konflik antar karyawan dalam satu departemen.

Selanjutnya menurut persepsi informan 13 dan 17 selaku konsumen yang telah memberikan tip, mereka menyatakan bahwa pemberian uang tip itu sama sekali bukan kewajiban, seperti pernyataan informan 13 "memberi tip itu tidak wajib apalagi bukan budaya Indonesia, tapi kalau saya ada uang lebih ya saya kasih, kenapa tidak" dan informan 17 menambahkan alasannya memberi tip karena keramahan dan kerja yang cekatan membuat beliau memberikan tip. Hal ini sesuai dengan pernyataan Mandias dan Kristanti (2006) bahwa motivasi memberi tip adalah salah satunya konsumen merasa menjadi baik hati karena konsumen merasa diperlakukan dan dilayani dengan baik, hal tersebut sejalan dengan pernyataan Greenberg (2014), pemberian tip adalah perilaku sukarela, pro-sosial yang dapat meningkatkan kepuasan konsumen oleh konsumen. Lebih lagi informan 18 menambahkan tujuan beliau memberi tip pada staffguest relation officer tersebut adalah "karena karyawan ramah, penanganan complain yang cepat, maka saya mengapresiasinya melalui pemberian tip”. Hal ini sejalan dengan pernyataan (Azar, 2007) bahwa tipyang diberikan adalah sebagai hadiah setelah pelayanandilakukan seperti kecepatan penanganan masalah yang diselesaikan serta konsumen yang merasa puas terhadap pelayanan yang telah diterimanya.

\section{SIMPULAN DAN SARAN}

\section{Simpulan}

Berdasarkan wawancara dan pengumpulan data mengenai persepsi karyawan terhadap budaya tipping di front office department, maka dapat ditarik simpulan bahwa terdapat dua sistem pembagian tip : no sharing of tips (individual) dan equal sharing of tips (kolektif), tip mampu meningkatkan motivasi karyawan dalam bekerja, tipjuga bisa menimbulkan konflik antar staff dalam satu hotel jika sistem pembagiannya tidak diatur secara tepat. Tip yang diberikan oleh tamu bukan merupakan tujuan utama dalam bekerja 
sertasama sekali tidak mempengaruhi kualitas layanan yang diberikan sebelum maupun sesudah menerima tip. Bagi konsumen, tip adalah penghargaan (personal achievement), uang sukarela, pemberian motivasi kerja, tambahan gaji untuk tabungan dan bukan menjadi alat yang digunakan tamu untuk mendapatkan pelayanan ekstra tetapi lebih merupakan apresiasi tamu terhadap pelayanan prima yang diberikan karyawan.

Pelayanan prima yang menjadi indikator tamu memberikan tip sebagai apresiasinya ialah sikap karyawan yang sopan, ramah, dan cepat tanggap dalam mengatasi komplain selama mereka menginap di Hotel tersebut.

\section{Saran}

Dari simpulan yang ada mengenai persepsi budaya tipping di departemen front office, maka peneliti memberikan beberapa saran antara lain pihak hotel dapat meminta masukan dan saran dari para karyawan akan sistem tipping secara berkala. Hal ini dilakukan agar pihak manajemen dapat melihat cara pandang karyawan terhadap sistem tipping yang berlaku. Manajemen hotel sebaiknya melakukan sistem pembagian equal sharing tips untuk karyawan di departemen lain yang berhubungan erat dengan front office department yang dibagi merata agar tidak terjadi konflik jangka panjang. Untuk melatih budaya adil dan jujur tiap karyawan, perlu pantauan yang komprehensif dari manajemen front office agar kegiatan ini berjalan sesuai dengan maksud dan tujuan dari tipping itu sendiri.

\section{DAFTAR PUSTAKA}

Azar, O. H. (2003). The implications of tipping for economics and management. In International Journal of Social Economics. https://doi.org/10.1108/0306829031049287 8

Azar, O. H. (2007). Why pay extra? Tipping and the importance of social norms and feelings in economic theory. Journal of Socio-Economics.

https://doi.org/10.1016/j.socec.2005.11.046

Badan Pusat Statistik Jawa Timur (2017). Tingkat Penghunian Kamar (TPK) Hotel di Jawa Timur Dirinci Menurut Bulan dan Jenis Hotel, Tahun 2017 Diakses 14 Maret 2019 dari

https://www.bps.go.id/publication/2018/09 /14/fb1879d84076764094eb1d83/tingkat- penghunian-kamar-hotel-2017.

Conlin, M., Lynn, M., \& O’Donoghue, T. (2003). The norm of restaurant tipping. Journal of Economic Behavior and Organization. https://doi.org/10.1016/S01672681(03)00030-1

Duman, B., \& D. Pulliam. (2006). Employers get drawn into IRS effort to collect tax on tips. Practical Tax Strategies. 76(6): 345-351

Gatta. M. (2009). Restaurant servers, tipping and resistance.Qualitive Research in Accounting \& Management. 6(3), $70-82$.

Goldsmith, A, D. Nickson, D. Sloan, \& R.C. Wood. (2002). Human resource management for hospitality services. United Kingdom: Thomson.

Greenberg, J. (2014). The Effects of Tipping on Consumers Satisfaction with Restaurant. (https://www.questia.com/read/1G1571516720/the-effects-of-tipping-onconsumers-satisfaction) (Diakses 13 Mei 2019; pk.16.06)

Kwortnik, R., M. Lynn \& M. Sturman. (2011). Voluntary tipping and selective attraction and retention of service workers in the united states: An application of the ASA model. International Journal of Human Resources Management. 22(9), 1887 1901.

Lin, I. Y., \& Namasivayam, K. (2011). Understanding restaurant tipping systems: A human resources perspective. International Journal of Contemporary Hospitality Management. https://doi.org/10.1108/0959611111116753 3

Lynn, M. (2001). Restaurant tipping and service quality A tenuous relationship. The Cornell Hotel and Restaurant Administration Quarterly. https://doi.org/10.1016/s00108804(01)90006-0

Lynn, Michael, \& Sturman, M. (2010). Tipping and service quality: A within-subjects analysis. Journal of Hospitality and Tourism Research. https://doi.org/10.1177/1096348009350637

Lynn, M, 2014. Service gratuities and tiping: A motivational frame work.Journal of Economics Psychology.

Mandias, R. dan M. Kristanti. (2006). Analisa Faktor-Faktor Yang Mempengaruhi Pemberian Tip Oleh Pelanggan Asing Pada Metode Self Service Di Starbucks Coffee 
Discovery Mall-Bali Dan Metode Table Dissertation.

Service Di The Wave Coffee BarBaliJurnal Manajemen Perhotelan. 2(1) : 27-35

Matthews, A. (2005). To tip or not to tip? It depends on the profession.(https://www.indiannewengland .com/To.Tip.Or.Not.To.Tip.It.Depends.On. The.Profession-677309.shtml) (Diakses 17 April 2019; pk 11.32)

Mochklas, M., \& Wibowo, T.S. (2018). DasarDasar Manajemen Membangun Organisasi. Surabaya: TS. Publisher

Namasivayam, K., \& Upneja, A. (2007). Employee preferences for tipping systems. Journal of Foodservice Business Research. https://doi.org/10.1300/J369v10n02_07

Obringer, L. A. 2002. How Tipping Works. (http://people.howstuffworks.com/tipping. html) (Diakses 30 April 2019; pk 13. 55)

Oktaviani, M., \& Mochklas, M. (2019). Free Cash Flow, Size, and Earning Management. 1st Borobudur International Symposium on Humanities, Economics and Social Sciences (BIS-HESS 2019, Advances in Social Science, Education and Humanities Research, volume 436

Saifudin, A.B., Fatihudin, D., \& Mochklas, M. (2020). Dampak Lingkungan Kerja Dan Motivasi Kerja Terhadap Kepuasaan Karyawan Perusahaan Logistik. E-Jurnal Ekonomi dan Bisnis Universitas Udayana, 9(6): 509-524

Sugiarto, Y. A. (2015). Analisa Budaya Tipping di Hotel dilihat dari Persepsi Karyawan dan Pengaruhnya terhadap Job Fairness dan Kualitas Layanan.Skripsi. Surabaya: Fakultas Ekonomi. Universitas Kristen Petra

Sugihartono, Rohmah. S dan Agus. F. (2007). Psikologi Pendidikan. Yogyakarta: Uny Press.

Sugiyono. 2015. Metode Penelitian Tindakan Komprehensif. Bandung. Alfabeta.

Van Den Bos, K. (2001). Uncertainly management: the influence of uncertainly salience on reactions to perceived procedural fairness. Journal of Personality and Social Psychology. 80(6), 931 - 945.

Waidi. (2006). The art of re-engineering your mind for success. Jakarta: Gramedia.

Whaley, J. E. (2011). What's in a Tip? An Exploratory Study of the mOtivations Driving Consumer Tipping Behavior. 